\title{
CASE REPORT: HENOCH-SCHÖNLEIN PURPURA TRIGGERED BY SARS-COV-2 INFECTION
}

Jean Paulo Veronese de Souza", Vanessa de Quadros Martins', Karol Levien Dora², Fernanda de Oliveira Chiaradia², Marilia Comissoli Brust², Deise Marcela Piovesan', Bárbara Mendes da Silva', Marcelo Maltchik', Roberta Casanova Wilhelms', Camila Schafer ${ }^{1}$, Markus Bredemeier', lloite Maria Scheibel ${ }^{2}$

1. Hospital Nossa Senhora da Conceição, Porto Alegre (RS), Brazil. 2. Hospital da Criança Conceição, Porto Alegre (RS), Brazil.

${ }^{\star}$ Corresponding author: jeanpvs@gmail.com

\section{BACKGROUND}

Henoch-Schönlein purpura (HSP) results from vascular inflammation due to immunoglobulin A (IgA) deposition after an environmental trigger. Approximately $50 \%$ of cases are preceded by viral or bacterial infections of the upper airways. Manifestations of the disease classically involve purpura, arthralgia, and peripheral edema; visceral edema (which may cause intussusception) and renal complications [systemic arterial hypertension (SAH) and chronic kidney disease] may be present. We report a case of a child who developed the syndrome after infection by the SARSCoV-2 virus.

\section{CASE REPORT}

A 5-year-old boy, with no identified infectious prodrome, arrived at the emergency department with a report of abdominal pain and constipation, which, after 3 days, evolved with fever, diarrhea, vomiting and purplish lesions with an ascending pattern in the lower limbs and abdomen, followed by edema of hands and feet. About 10 days after the onset of the condition, the patient presented worsening abdominal pain and an increase in the area committed by purpura. Abdominal ultrasound showed edema of loops of the small bowel, and blood tests showed elevated liver enzymes, without other remarkable laboratory changes. During hospitalization, the patient presented a worsening clinical condition with prostration, arthralgia, testicular pain and progression of edema extending to the gluteus, scrotum, face and forearms. During etiological evaluation, PCR for SARS-CoV-2 tested positive, and it was considered the main trigger for HSP in this case. The management consisted of a "minipulse" with methylprednisolone ( $8 \mathrm{mg} / \mathrm{kg}$, single dose, intravenously), followed by oral corticosteroid therapy, with showed effectiveness improving the clinical manifestations and the general condition of the patient, despite the persistence of an extensive purpuric rash, even 30 days after the disease onset.

\section{CONCLUSION}

We report a case of HSP, occurring after infection by the SARS-CoV-2 virus, presenting exuberant clinical manifestations but benign evolution. Further studies are needed to define the role of SARS-CoV-2 as a potential trigger of HSP. 